\title{
Preparing to introduce the varicella vaccine into the Italian immunisation programme: varicella-related hospitalisations in Tuscany, 2004-2012
}

S Boccalini ${ }^{1}$, P Bonanni ${ }^{1}$, A Bechini ${ }^{1}$

1. Department of Health Sciences, University of Florence, Florence, Italy

Correspondence: Paolo Bonanni (paolo.bonanni@unifi.it)

Citation style for this article:

Boccalini S, Bonanni P, Bechini A. Preparing to introduce the varicella vaccine into the Italian immunisation programme: varicella-related hospitalisations in Tuscany, 2004-2012. Euro Surveill. 2016;21(24): pii=30257. DOI: http://dx.doi.org/10.2807/1560-7917.ES.2016.21.24.30257

Article submitted on 22 April 2015 / accepted on 02 February 2016 / published on 16 June 2016

A universal immunisation programme against varicella in the form of the measles-mumps-rubella-varicella (MMRV) vaccine for toddlers aged 13-15 months was introduced in Tuscany in July 2008. An assessment of the impact of this programme on varicella-related hospitalisations 4 years after its introduction could further support its adoption at a national level. The hospitalisation data were analysed in two periods: pre-vaccination (2004-2007) and vaccination period (2009-2012). The high coverage of the vaccines $(84 \%$ in 2012) resulted in a significant decline in notifications, from $33,114(2004-2007)$ to 13,184 cases (2009-2012), and also of hospitalisations, from 584 (pre-vaccination period) to 325 (vaccination period). The hospitalisation rate was 4.1 per $100,000(95 \%$ confidence intervals $(\mathrm{Cl}): 3.4-4.7)$ before the introduction of vaccination, which dropped to 2.2 per 100,000 (95\% Cl: 1.7-2.7) in the vaccination period (hospitalisation risk ratios: $0.54 ; 95 \% \mathrm{Cl}: 0.472-0.619)$. The reduction was most significant in the youngest age groups. The introduction of universal vaccination has already led to a significant decline in hospitalisations due to varicella after just 4 years of implementation. Hospitalisation rates fell noticeably among younger individuals involved in the vaccination programme. The decrease in hospitalisation rate in the older age groups suggests a possible indirect protection.

\section{Introduction}

Varicella (chickenpox) is the primary manifestation of infection with the varicella zoster virus (VZV) and is a widespread and highly contagious infectious disease. Today, varicella is recognised as the most common exanthematic disease in children in Italy, with an estimated number of 500,000 new cases each year $[1,2]$. Seroprevalence studies confirm that VZV infection is still predominantly a paediatric infection in Italy, and that there are no substantial differences between blood samples collected in 1996-1997 and those collected in 2003-2004 [2,3].
An effective and safe monovalent varicella vaccine has been available in Italy since 1995. However, varicella immunisation has not been widely administered in Italy in the previous decades. In the National Vaccination Plan 2005-2007, the varicella vaccine was recommended only to individuals with a high risk of complications and to susceptible adolescents [4]. However, in order to avoid a shift in the median age of VZV infection towards adulthood, the plan advised introduction of routine childhood varicella vaccination in regions that have been able to achieve and maintain high vaccination coverage against measles, mumps and rubella (MMR) [4]. As a result of these indications, universal immunisation against varicella was not homogeneously implemented at the national level $[5,6]$. According to an earlier survey of vaccination coverage carried out in Italy by the National Institute of Health (Istituto Superiore di Sanità), the reported childhood vaccination coverage, involving one dose of the varicella vaccine at 24 months of age, was only $17.1 \%$ (range: $15 \cdot 7-18.6 \%$ ) in Italy in 2008 [7].

In the Italian National Vaccination Plan 2012-2014, (which is the schedule currently being used in 2016) the implementation of universal varicella vaccination at the national level was pushed back until such time when the monitoring and data evaluation of the pilot programmes carried out in some Italian regions (Basilicata, Calabria, the autonomous province of Bolzano, Puglia, Sardinia, Sicily, Tuscany, and Veneto) would be available [8]. Assessment of the epidemiological and economic impact of immunisation against varicella through these regional programmes will enable the rationale for the aforementioned decision to be validated. At the time of publication, the evaluation and related implementation at the national level have not yet been performed.

Tuscany was one of the first Italian regions to introduce and implement a universal vaccination programme 


\section{FIGURE 1}

Hospitalisation rate for varicella diseases and incidence of varicella, Tuscany, Italy, 2004-2012

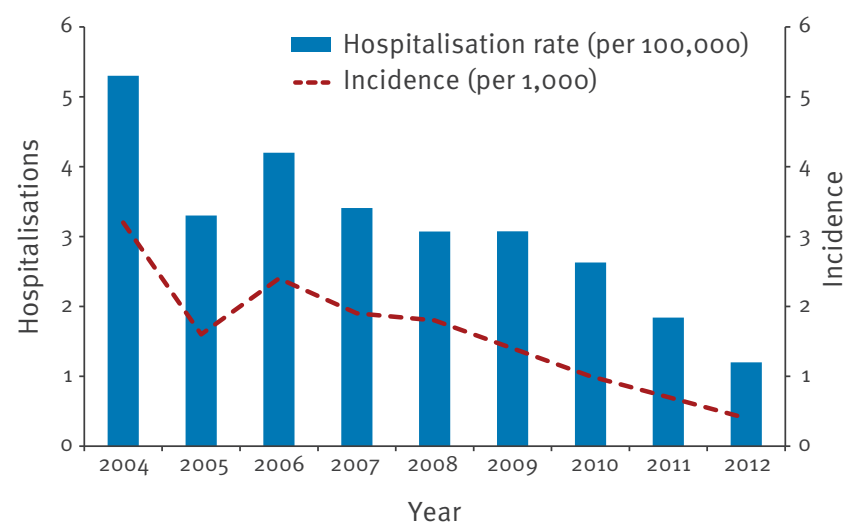

against varicella with a combined MMRV vaccine for children aged 13-15 months (first dose) and 5 to 6 years (second dose), in July 2008 [9]. The impact of this preventive intervention was evaluated 4 years after the implementation.

In particular, the objective of our study is to evaluate the impact of universal varicella vaccination in Tuscany by analysing all varicella-related hospitalisations reported in the period $2004-2012$.

\section{Methods}

The hospital discharge records related to varicella were analysed in order to evaluate the impact of universal varicella vaccination on the hospitalisation rate in Tuscany. Hospitalisation data for 2004-2012 were collected from the Tuscan regional database. In particular, all hospitalised cases for varicella or its complications, as a primary or secondary discharge diagnosis, with the following ICD-9-CM codes (2002 and 2007) were examined: 052.0 (post-varicella encephalitis), 052.1 (varicella (haemorrhagic) pneumonitis), 052.2 (postvaricella myelitis), 052.7 (varicella with other specified complications), 052.8 (varicella with unspecified complication), and 052.9 (varicella without complication) [10].

For each hospitalised case, the collected information included year of hospitalisation, age at time of discharge, sex, region of origin, local health unit, country of residence, hospital days, primary and up to five secondary diagnoses, and total cost of hospitalisation. The costs of hospitalisation correspond to the refunding by the region to the hospitals. Costs are calculated according to the diagnosis-related group (DRG), and also include the possible costs due to the additional days of hospitalisation in excess of the specific outlier threshold. Moreover, the resident population was grouped by age, as retrieved by the Italian National Institute of Statistics database, in order to calculate hospitalisation rates [11].
Hospitalisation data were compared with surveillance data obtained from the Tuscan regional database for varicella cases notified in Tuscany in the same period.

In addition, data on varicella vaccine coverage in children aged 24 months in the period 2008-2012 were included in the analysis. Data on vaccination coverage were also collected from the Tuscan regional database.

Varicella-related hospitalisations were analysed as follows: (i) in the entire period 2004-2012, in order to evaluate the trend over time; (ii) in two periods of 4 years each (the pre-vaccination period, 2004-2007; and the period following the vaccine's introduction, 2009-2012). Data from 2008, the transition year between the two periods mentioned above, were excluded from our analysis. The impact of universal varicella vaccination was assessed by calculating the hospitalisation risk ratios (HRRs) with a 95\% confidence interval (CI) (Mantel-Haenszel combined test).

\section{Results}

\section{Varicella vaccination in Tuscany}

Inclusion of the quadrivalent combined MMRV vaccine in the immunisation programme led to rapid achievement of high vaccine coverage against varicella in Tuscany, with a relevant dragging effect. In fact, varicella vaccination with MMRV or monovalent varicella vaccines for children at 24 months of age achieved high coverage soon after implementation: $75.5 \%$ in $2010,82.2 \%$ in 2011 , and $84.0 \%$ in 2012 .

\section{Varicella cases and hospitalisations}

In Tuscany, 52,738 varicella cases were notified to the Regional Health Authority in 2004-2012. A dramatic overall reduction in the number of notifications was reported between 2004 (11,445 cases) and 2012 $(1,502$ cases). The number of reported varicella cases in the vaccination period $(13,184$ cases $)$ has been reduced by more than half $(60.2 \%$ reduction) of that in the pre-vaccination period $(33,114$ cases). The average incidence rate has declined from 2.30 cases (95\% $\mathrm{Cl}: 2.25-2.35)$ to 0.89 cases (95\% Cl: $0.86-0.92)$ per 1,000 inhabitants.

For the same period in 2004-2012, a total of 1,022 hospital discharge records related to varicella or its complications were found in Tuscany. The number of hospitalisations due to varicella diseases showed a decreasing trend over the 9 years analysed: 189 hospitalisations for varicella ( 5.3 hospitalised cases/100,000 inhabitants; 95\% Cl: 4.5-6.1) were reported in 2004 and 44 in 2012 (1.2/100,000 inhabitants; 95\% Cl: $0.8-$ 1.6). In other words, there was a substantial reduction in the number of hospitalisations (by $77 \%$ ) between 2004 and 2012. The incidence of notified varicella cases and the rate of hospitalised cases for varicella diseases showed the same trend in the period 20042012 in Tuscany (Figure 1). 
Hospitalisation rates for varicella, by age group, Tuscany, Italy, 2004-2012

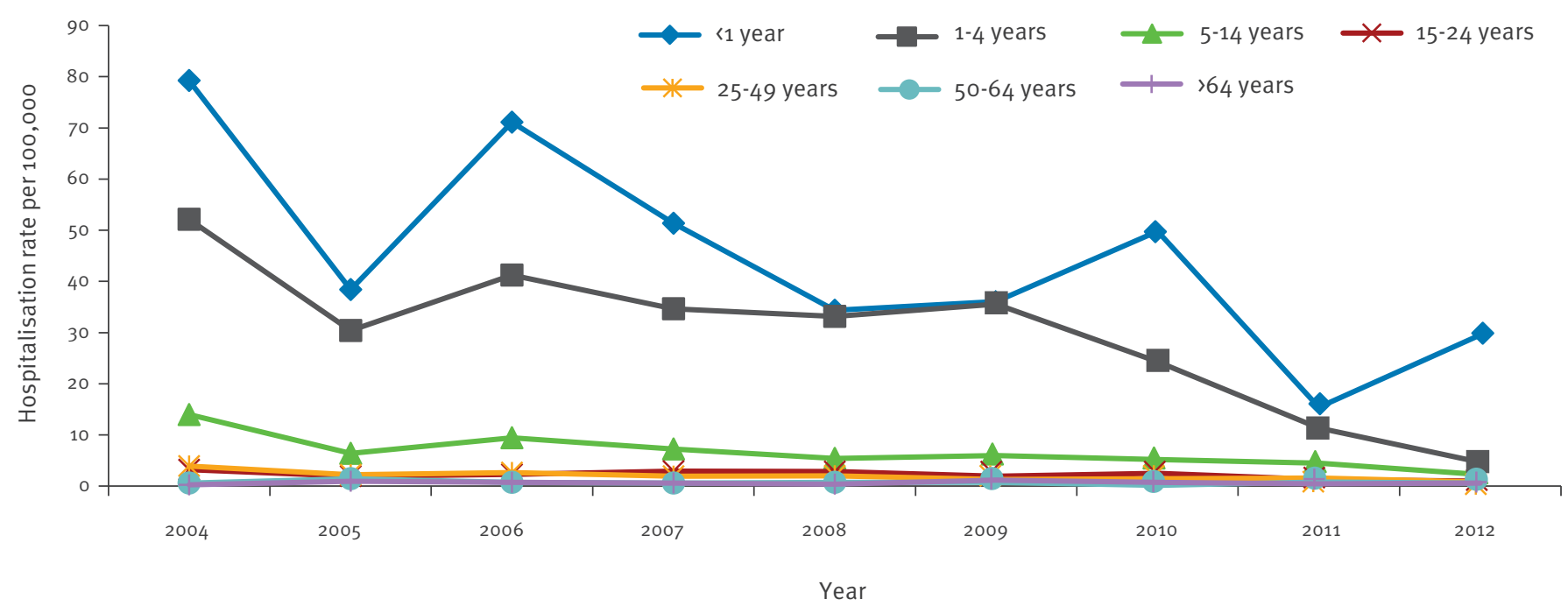

In the pre-vaccination period (2004-2007), there were 584 hospitalised cases related to varicella or its complications in Tuscany, while in the vaccination period (2009-2012) there were 325. A total reduction of $44 \%$ (259 fewer cases) in the number of hospitalisations due to varicella was observed between 2009 and 2012. In particular, the average hospitalisation rate for varicella diseases was 4.1 per 100,000 ( $95 \% \mathrm{Cl}: 3.4-4.7)$ in the period before the introduction of varicella vaccination in Tuscany. This dropped to 2.2 per 100,000 (95\% Cl: 1.7-2.7) in the vaccination period (HRR: 0.54; $95 \%$ $\mathrm{Cl}: 0.47-0.62)$.

Hospitalisations for varicella diseases analysed by age at time of discharge

In the period 2004-2012, the hospitalisation rates related to varicella or its complications showed a downward trend in almost all age groups, especially for children under 14 years of age. Children aged between 1 and 4 years, who had historically been affected by varicella diseases and were enrolled in the current universal programme of varicella vaccination in Tuscany, appeared to be the age group that received the greatest benefit from vaccination (a net reduction in hospitalised cases by $90 \%$ in the 9 -year period, from 60 cases in 2004 to six cases in 2012, corresponding to a hospitalisation rate of 52.1 (95\% Cl: 38.9-65.3) and 4.6 (95\% Cl: 0.9-8.4) per 100,000 inhabitants respectively) (Figure 2).

On comparing the pre-vaccination and vaccination period data, the most relevant reduction (>20\%) in the rate of hospitalisation due to varicella diseases was again reported in children below 5 years of age (Table).

Hospital discharge records for varicella diseases analysed by discharge code

The hospital discharge records for primary and secondary diagnoses of varicella or its complications in the study period (2004-2012) were analysed. Among the
1,022 hospitalised cases in Tuscany, a total of 1,041 varicella-related codes (ICD-9-CM) were reported. Of these, 19 hospitalised cases had more than one code identifying varicella diseases in the discharge diagnosis. The most frequently reported discharge code was varicella without complication (052.9). In the period 2004-2012, there were no hospitalisations for postvaricella myelitis (ICD-9-CM 2007 code 052.2).

In the switch from the pre-vaccination years (20042007) to the vaccination period (2009-2012), a net reduction in hospitalised cases was evident for all discharge codes related to varicella. The greatest reduction in the number of hospitalised cases ( 178 cases) between the two periods (2004-2007 vs 2009-2012) pertained to the discharge diagnosis of varicella without complications (052.9) (Figure 3). In fact, hospitalisations for this diagnosis decreased by $10.5 \%$ in individuals aged 1-14 years who were involved in the vaccination programme.

\section{Total days of hospitalisation for varicella diseases}

In the period $2004-2012$, a total of 1,022 patients hospitalised for varicella or its complications in Tuscany remained in the hospital for 6,112 days (an average of six hospital days per patient). The total number of hospital days showed a clear downward trend in the 9 years analysed. In particular, while in 2004 patients were admitted for 960 days in total, in 2012 the total number of hospital days had decreased to 378 days, with an overall reduction of $61 \%$ between the first and the last year analysed in the study. In the pre-vaccination period (2004-2007), the total number of days hospitalised was 3,388; this number decreased to 2,021 in the vaccination period (2009-2012), showing a reduction of $40 \%$ ( 1,367 days fewer). The average number of hospital days per patient ranged from 5.8 to 6.6 in the pre-vaccination and vaccination periods. 


\section{FIGURE 3}

Number of hospitalised cases for varicella diseases, by diagnosis code $\mathrm{a}^{\mathrm{a}}$, Tuscany, Italy, in the pre-vaccination (2004-2007) and vaccination periods (2009-2012)

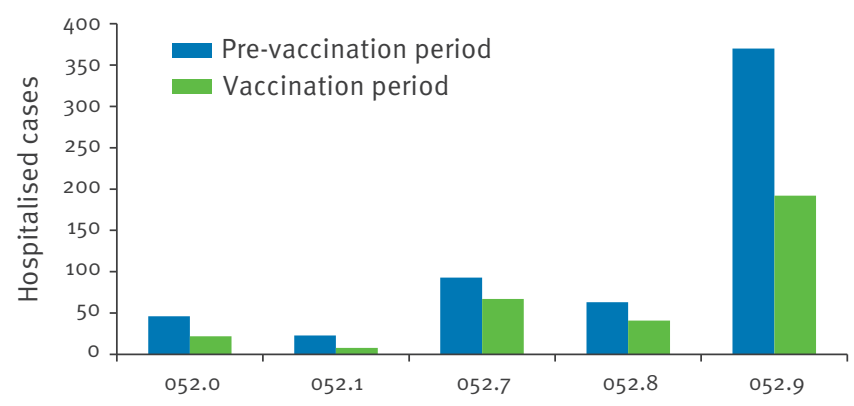

a Reference [10].

International classification of diseases, ninth revision, clinical modification (ICD-9-CM) codes: 052.0 (post-varicella encephalitis), 052.1 (varicella (haemorrhagic) pneumonitis), 052.2 (postvaricella myelitis), 052.7 (varicella with other specified complications), 052.8 (varicella with unspecified complication), and 052.9 (varicella without complication)

\section{FIGURE 4}

Total cost of hospitalisation for varicella diseases, by age group, Tuscany, Italy, pre-vaccination (2004-2007) and vaccination periods (2009-2012)

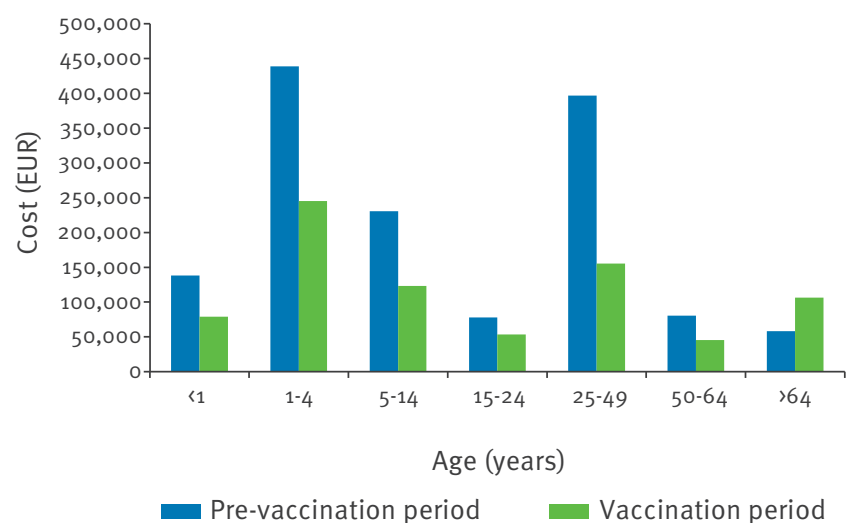

\section{FIGURE 5}

Cost per hospitalised case for varicella diseases, Tuscany, Italy, 2004-2012

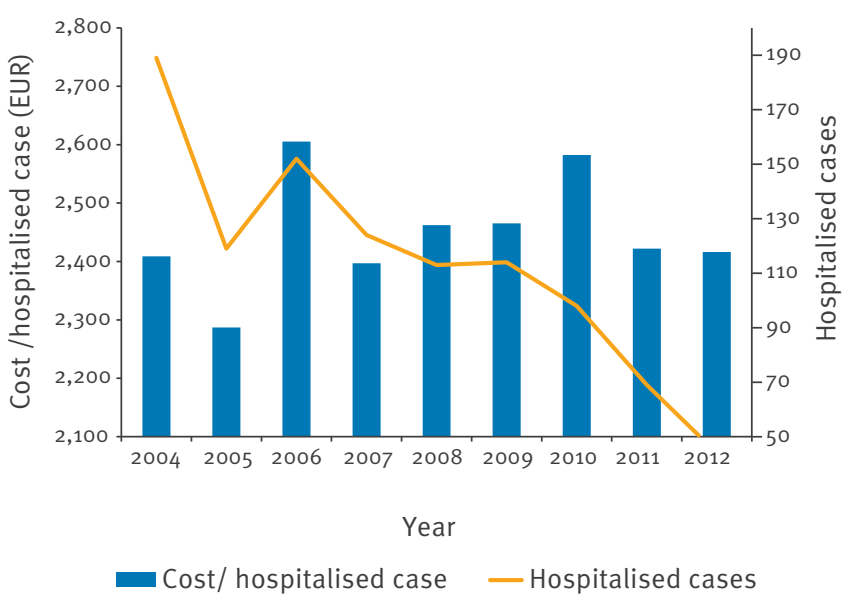

Cost of hospitalisations due to varicella diseases

In the period 2004-2012, the cost of the 1,022 hospitalisations for varicella or its complications in Tuscany amounted to EUR 2,506,422 (EUR 2,452 per patient on average). The total annual cost of hospitalisation has shown a decreasing trend in the 9 years analysed, similar to the trend in hospitalised cases. In particular, while 189 hospitalisations for varicella occurred in 2004, incurring a cost of EUR 455,267 , in the final year of the study 44 patients were hospitalised for a total cost of EUR 106,311, an overall cost reduction of $77 \%$. In the pre-vaccination period (2004-2007) the total cost of hospitalisation due to varicella was EUR $1,420,657$ (EUR 355,164/year). In the vaccination period (2009-2012), the cost decreased to EUR 807,535 (EUR $201,884 /$ year). Therefore, hospital costs declined by $43 \%$, creating total savings of EUR 613,121 , or EUR $153,280 /$ year.

In the switch from the pre-vaccination period (20042007) to the vaccination period (2009-2012), a reduction in the total cost of hospitalisations for varicella diseases was reported in all age groups in Tuscany (Figure 4). However, the cost of hospitalisation increased among individuals over 64 years of age, though the number of hospitalised patients in this age group had not changed much from the pre-vaccination period (21 cases) to the vaccination period (25 cases). This slight increase in costs is mainly attributable to the specific case of an 80-year old patient whose primary diagnosis was pulmonary insufficiency, with secondary diagnoses including generalised convulsive epilepsy, cerebrovascular disease, a kidney disorder, and post-varicella encephalitis. This patient's hospital costs amounted to EUR 34,724. The greatest reduction of hospitalisation costs in absolute number (EUR 241,267 ) concerns the age group of $25-49$ years (data not shown).

In the period 2004-2012, although the number of hospitalised cases and the total annual cost of hospitalisation declined to a great extent, the cost per hospitalised case seemed to show a slight increasing trend over the 9 years analysed (Figure 5). In the pre-vaccination period (2004-2007), the average cost of hospitalised cases was EUR 2,433 per patient, while in the period of varicella vaccination (2009-2012), this cost increased by $2 \%$ to EUR 2,485, with an increment of EUR 52 in the average hospitalisation cost of each patient.

\section{Discussion and conclusions}

The routine immunisation of toddlers against varicella has not yet been widely implemented in Europe. Assessment of the epidemiology and disease burden of varicella in each country and evidence for the effectiveness of varicella vaccination could provide support for decision on implementation of routine childhood programmes [12]. Generally, only a small percentage of people infected with varicella diseases are hospitalised in Italy. However, the period 2000-2003 saw an 
Hospitalisations for varicella diseases, by age, and hospitalisation risk ratios with 95\% CI, Tuscany, Italy, pre-vaccination (2004-2007) and vaccination periods (2009-2012)

\begin{tabular}{|c|c|c|c|c|c|c|}
\hline \multirow[b]{2}{*}{ Age group } & \multicolumn{2}{|c|}{ Pre-vaccination period $2004-2007$} & \multicolumn{2}{|c|}{ Vaccination period $2009-2012$} & \multirow[b]{2}{*}{ HRR } & \multirow[b]{2}{*}{$95 \% \mathrm{Cl}$} \\
\hline & Hospitalisations & $\begin{array}{l}\text { Average rate per } \\
100,000\end{array}$ & Hospitalisations & $\begin{array}{l}\text { Average rate per } \\
100,000\end{array}$ & & \\
\hline <1 year & 73 & 59.6 & 42 & 32.7 & 0.55 & $0.38-0.80$ \\
\hline $1-4$ years & 189 & 39.5 & 99 & 18.9 & 0.48 & $0.38-0.61$ \\
\hline $5-14$ years & 105 & 9.2 & 55 & 4.5 & 0.48 & $0.35-0.67$ \\
\hline $15-24$ years & 32 & 2.6 & 21 & 1.7 & 0.64 & $0.37-1.19$ \\
\hline $25-49$ years & 141 & 2.7 & 67 & 1.3 & 0.47 & $0.35-0.63$ \\
\hline $50-64$ years & 23 & 0.8 & 16 & 0.5 & 0.67 & $0.35-1.26$ \\
\hline$>64$ years & 21 & 0.6 & 25 & 0.7 & 1.14 & $0.64-2.04$ \\
\hline Overall & 584 & 4.1 & 325 & 2.2 & 0.54 & $0.47-0.62$ \\
\hline
\end{tabular}

$\mathrm{Cl}$ : confidence interval; HRR: hospitalisation risk ratio.

annual average of 1,575 hospitalisations where varicella was the primary diagnosis $(1,521$ hospitalisations and 54 day-hospital admissions) with a mean hospital stay of 5.3 days per person [2]. Approximately one-third of these cases occurred in people older than 14 years and could have been prevented through a programme of universal vaccination, including an active offer of varicella vaccine to adolescents and adults at high risk without any anamnestic history of varicella diseases [2].

The results of our study show that the introduction of a universal varicella vaccination with MMRV vaccine in Tuscany for all newborns has already resulted in a significant reduction in varicella notifications as well as in the number of hospitalisations due to varicella and related costs, within the first 4 years of implementation. In particular, the current analysis highlights that the number of hospitalised cases has been greatly reduced, especially among younger individuals who were involved in the vaccination programme. However, a positive impact of vaccination on the hospitalisation rate is also evident in other age groups, suggesting a herd immunity effect. Our data on significant reduction of hospitalisation due to varicella in adults are compatible with the results published in Canada [13] and the United States (US) [14] but contradict the hospitalisation data in Germany, where results do not demonstrate herd protection against varicella with $87 \%$ vaccination coverage [15]. In addition, the absence of a shift of infection time to the older age groups could be explained by the high vaccination coverage among children. Comparing hospitalisation for uncomplicated varicella (the most frequent discharge diagnosis) in the pre-vaccination period (2004-2007) and in the vaccination period (2009-2012), a clear reduction is evident, thus suggesting that the slight increase in the cost per hospitalised patient might be due to a higher chance that only the most severe cases were hospitalised during the vaccination period.
Limitations of the study are mainly due to the fact that our data on hospitalisations are based on administrative data. A greater appropriateness of hospital admissions during the examined period cannot be excluded as an additional factor in the reduction of hospitalisation rate. Another possible limitation is that varicella may have been coded as zoster or vice versa, even though we included only hospitalisation related to varicella in the analysis. Therefore, the magnitude of the decline implies a marked positive effect of the rapid increase in the vaccination coverage, achieved due to the availability of the quadrivalent MMRV vaccine.

Our study confirms the remarkably favourable clinical impact on notified cases and varicella-related hospitalisations reported in two other Italian regions (Sicily and Veneto), a few years after the implementation of the immunisation programme. Sicily was the first Italian region to offer a universal active vaccination against varicella free of charge to infants at 15 months of age and to all susceptible adolescents at 12 years of age, in January $2003[16,17]$.

The Veneto region adopted active and free universal varicella vaccination in January 2005 for children aged 14 months (offering a second dose at the age of 6 years), and a catch-up programme for adolescents aged 12 years. The rapid achievement of high (but not optimal) coverage of vaccination against varicella (78.6\% in the 2008 birth cohort) resulted in a net decrement (halving) of the varicella incidence, both in the 0-14 year age group and in the general population, within 4 years of the introduction of the varicella vaccination programme. Furthermore, in this region, hospitalisation due to varicella infection also significantly decreased within 1.5 years of the introduction of the universal varicella vaccination, confirming a significant positive impact of universal varicella vaccination in this Italian region [18-20].

In addition, the reduction in varicella cases and number of related hospitalisations highlighted in Sicily, Veneto, Tuscany, and recently in other Italian regions [21,22], 
after the introduction of the universal varicella immunisation programme, had already been observed in other countries. In the US, universal varicella vaccination with one-dose (1996) and two-dose (2006) schedules for children was demonstrated to have a clear and significant impact on the disease burden of VZV infection within a few years of implementation [23-28]. In our recent data, obtained a few years after the start of the varicella immunisation programme, the number of hospitalisations due to varicella shows a trend similar to the results reported in the US [29-35].

A relevant reduction of VZV infections and disease complications has also been observed in Germany, which was the first European country to implement a routine universal vaccination programme against varicella in 2004 [36-38].

From an economic point of view, the universal vaccination of children in Tuscany led to savings amounting to EUR 613,121 over 4 years (EUR 153,280/year), considering only the potential costs of hospitalisations that were prevented by immunisation. In particular, a reduction in hospitalisation costs is evident in all age groups except for individuals over 64 years, where the high cost during the vaccination period can be mainly attributed to the previously described case of a patient aged 80 years who had other medical conditions and incurred hospitalisation costs amounting to EUR 34,724. However, the reported savings could be even more substantial if it is assumed that the real expense is $30-40 \%$ higher than the figure calculated through the DRG value, as shown by Azzari et al. [39]. In addition, in our study, we analysed only the cost of hospitalisations due to VZV infection: savings following vaccination would have greatly increased if we also included the other clinical costs and indirect costs due to productivity loss. Therefore, the data we collected in a real-setting scenario seem to confirm the favourable economic contribution of varicella immunisation in Italy, as previously reported in three Italian model-based evaluations [40-42]. Particularly in the mathematic simulation performed by Bonanni et al., a varicella vaccination programme with two doses for toddlers was predicted to lead to reduction by more than $80 \%$ in VZV infection and hospitalisation rate in a 30-year time horizon [42]. The results of our study show a $44 \%$ reduction in the rate of hospitalisation due to varicella within 4 years of the introduction of varicella vaccination, confirming the model's mathematical forecast.

In conclusion, our experience clearly supports the intention of the Italian health authorities to introduce a national universal routine vaccination against varicella. The use of the quadrivalent MMRV vaccine is a key element to achieving high vaccination coverage in a short period of time, thus speeding up the impact on disease incidence and related hospitalisations. The Italian regional vaccination programmes against varicella may also prove to be a useful example for other countries where the introduction of routine toddler vaccination is being considered.

\section{Acknowledgements}

The authors would like to thank Emanuela Balocchini, Lucia Pecori, Sara Gallicchio, Serenella Acciai, Cecilia Chiarugi and Silvia Callaioli (Tuscany Region Health Authority) for providing data on notification of varicella cases, hospitalisations and vaccination coverage. The authors are grateful to Cristina Taddei for her support in the statistical analysis.

\section{Conflict of interest}

All authors received fees from vaccine producers (GSK, SPMSD, Pfizer, Novartis) for taking part to advisory boards or expert meetings, and grants for acting as investigators (PB) in epidemiological studies co-funded by vaccine producers (Pfizer, GSK).

\section{Authors' contributions}

All the authors contributed equally in the design, collection and analysis of data.

\section{References}

1. Ciofi degli Atti ML, Rota MC, Mandolini D, Bella A, Gabutti $G$, Crovari P, et al. Assessment of varicella underreporting in Italy. Epidemiol Infect. 2002;128(3):479-84. DOI: 10.1017/ So950268802006878 PMID: 12113493

2. Gabutti G, Rota MC, Guido M, De Donno A, Bella A, Ciofi degli Atti ML, et al., Seroepidemiology Group. The epidemiology of Varicella Zoster Virus infection in Italy. BMC Public Health. 2008;8(1):372. DOI: 10.1186/1471-2458-8-372 PMID: 18954432

3. Gabutti G, Penna C, Rossi M, Salmaso S, Rota MC, Bella A, et al. , Serological Study Group. The seroepidemiology of varicella in Italy.Epidemiol Infect. 2001;126(3):433-40. DOI: 10.1017/S0950268801005398 PMID: 11467800

4. Conferenza permanente per i rapporti tra lo Stato, Regioni le Province Autonome di Trento e Bolzano Determinazione 3 marzo 2005. Accordo ai sensi dell'art 4 del decreto legislativo 28 agosto n.281, tra il Ministro della Salute e i Presidenti delle regioni e delle province autonome, concernente il Nuovo Piano Nazionale Vaccini 2005-2007. GU n86 del 14-04-2005- Suppl ordinario n63. [Permanent Conference for relations between the State, Regions and Autonomous Provinces of Trento and Bolzano. Determination March, 3rd 2005. Agreement under Article 4 of Legislative Decree August 28th, between the Minister of Health and the Presidents of Regions and Autonomous Provinces on the New National Plan 2005-2007 Vaccines. Official Bulletin n.86 April, 4th 2005. Ordinary suppl. N.63]. Italian. Available from: http://www.salute.gov.it/ imgs/C_17_pubblicazioni_543_allegato.pdf

5. D’Ancona F, Alfonsi V. Ciofi degli Atti ML. [Survey on vaccination strategies used in different Italian Regions, for the 7 -valent conjugate pneumococcal, meningococcal $C$ and varicella vaccines]. Italian. Ig Sanita Pubbl. 2006;62(5):48392.PMID: 17206224

6. Alfonsi V, D’Ancona F, Giambi C, Nacca G, Rota MC, Regional Coordinators for Infectious Diseases and Vaccinations. Current immunization policies for pneumococcal, meningococcal C, varicella and rotavirus vaccinations in Italy. Health Policy. 2011:103(2-3):176-83. DOI: 10.1016/j.healthpol.2011.10.002 PMID: 22030308

7. Istituto Superiore di Sanità [National Institute of Health] ICONA 2008: Indagine di COpertura vaccinale NAzionale nei bambini e negli adolescenti [ICONA 2008: Survey on national immunization coverage in children and adolescents]. 2008. Italian. Available from: http://www.iss.it/binary/publ/ cont/09_29_web.pdf

8. Ministero della Salute [Ministry of Health]. Piano Nazionale Prevenzione Vaccinale (PNPV) 2012-14 [National Preventive Vaccination Plan 2012-2014]. Gazzetta Ufficiale n. 47 del 12/03/2012 (Supplemento Ordinario). Italian. Available from: http://www.salute.gov.it/imgs/C_17_pubblicazioni_1721_ allegato.pdf 
9. Regione Toscana [Tuscany Region]. Aggiornamento direttive regionali in materia di vaccinazioni [Updating the regional guidelines on vaccinations]. Revoca delibere n. 1249 del 24/11/2003, n.379 del 7/3/2005 e n.1060 del 10/10/2000. Modifica delibera n. 1386 del 17/12/2001. Deliberazione Giunta Regionale del 27 dicembre 2007, n. 1020, Bollettino Ufficiale Della Regione Toscana, N. 2 del 9.1.2008. Italian. Available from: http://www.fimptoscana.org/system/files/delibera\%20 calendario\%2oregionale\%2027-12-2007_0.pdf

10. Centers for Disease Control and Prevention (CDC). International classification of diseases, ninth revision, clinical modification (ICD-9-CM). Atlanta, GA: CDC; 2010. Available from: http:// www.cdc.gov/nchs/icd/icdgcm.htm

11. Istituto nazionale di Statistica (ISTAT)[Italian National Institute of Statistics]. Geodemo. Italian resident population (20032012). [Accessed January 2015]. Italian. Available from: http:// demo.istat.it/

12. Bonanni P, Breuer J, Gershon A, Gershon M, Hryniewicz W, Papaevangelou V, et al. Varicella vaccination in Europe taking the practical approach. BMC Med. 2009;7(1):26. DOI: 10.1186/1741-7015-7-26 PMID: 19476611

13. Waye A, Jacobs P, Tan B. The impact of the universal infant varicella immunization strategy on Canadian varicella-related hospitalization rates.Vaccine. 2013;31(42):4744-8. DOI: 10.1016/j.vaccine.2013.08.022 PMID: 23973325

14. Lopez AS, Zhang J, Brown C, Bialek S. Varicella-related hospitalizations in the United States, 2000-2006: the 1-dose varicella vaccination era.Pediatrics. 2011;127(2):238-45. DOI: 10.1542/peds.2010-0962 PMID: 21199857

15. Siedler A, Dettmann M. Hospitalization with varicella and shingles before and after introduction of childhood varicella vaccination in Germany. Hum Vaccin Immunother. 2014;10(12):3594-600. DOI: 10.4161/hv.34426 PMID: 25483695

16. Giammanco G, Ciriminna S, Barberi I, Titone L, Lo Giudice $M$, Biasio LR. Universal varicella vaccination in the Sicilian paediatric population: rapid uptake of the vaccination programme and morbidity trends over five years. Euro Surveill. 2009;14(35):19321.PMID: 19728978

17. Cuccia M, Pollina Addario S, Cernigliaro A, Palmigiano V. Ospedalizzazione per varicella in Sicilia dopo l'introduzione della vaccinazione [Hospitalization for varicella in Sicily after the introduction of vaccination]. Bollettino Epidemiologico Nazionale (Ben) Notiziario ISS Volume 22 numero 3, Marzo 2009. Italian. Available from: http://www.epicentro.iss.it/ ben $/ 2009 / \mathrm{marzo} / 1$.asp

18. Baldo V, Ferro A, Napoletano G, Milani S, Bertoncello L, Baldovin $\mathrm{T}$, et al. Universal varicella vaccination in the Veneto Region, Italy: launch of a programme targeting all children aged 14 months and susceptible adolescents. Euro Surveill. 2007;12(11):E071101.3.PMID: 17997908

19. Baldo V, Baldovin T, Russo F, Busana MC, Piovesan C, Bordignon G, et al. Varicella: epidemiological aspects and vaccination coverage in the Veneto Region. BMC Infect Dis. 2009;9(1):150. DOI: 10.1186/1471-2334-9-150 PMID: 19737419

20. Pozza F, Piovesan C, Russo F, Bella A, Pezzotti P, Emberti Gialloreti L. Impact of universal vaccination on the epidemiology of varicella in Veneto, Italy.Vaccine. 2011;29(51):9480-7. DOI: 10.1016/j.vaccine.2011.10.022 PMID: 22015389

21. Tafuri S, Fortunato F, Cappelli MG, Cozza V, Bechini A, Bonanni $P$, et al. Effectiveness of vaccination against varicella in children under 5 years in Puglia, Italy 2006-2012. Hum Vaccin Immunother. 2015;11(1):214-9. DOI: 10.4161/hv.36153 PMID: 25483538

22. Bechini A, Boccalini S, Baldo V, Cocchio S, Castiglia P, Gallo $\mathrm{T}$, et al. Impact of universal vaccination against varicella in Italy. Hum Vaccin Immunother. 2015;11(1):63-71. DOI: 10.4161/ hv.34311 PMID: 25483517

23. Seward JF, Watson BM, Peterson CL, Mascola L, Pelosi JW, Zhang JX, et al. Varicella disease after introduction of varicella vaccine in the United States, 1995-2000. JAMA. 2002;287(5):606-11. DOI: 10.1001/jama.287.5.606 PMID: 11829699

24. Marin M, Güris D, Chaves SS, Schmid S, Seward JF, Advisory Committee on Immunization Practices, Centers for Disease Control and Prevention (CDC). Prevention of varicella: recommendations of the Advisory Committee on Immunization Practices (ACIP).MMWR Recomm Rep. 2007;56(RR-4):1-40. PMID: 17585291

25. Centers for Disease Control and Prevention (CDC). Evolution of varicella surveillance--selected states, 2000-2010.MMWR Morb Mortal Wkly Rep. 2012;61(32):609-12.PMID: 22895384

26. Chaves SS, Lopez AS, Watson TL, Civen R, Watson B, Mascola $L$, et al. Varicella in infants after implementation of the US varicella vaccination program. Pediatrics. 2011;128(6):1071-7. DOI: 10.1542/peds.2011-0017 PMID: 22123875
27. Kattan JA, Sosa LE, Bohnwagner HD, Hadler JL. Impact of 2-dose vaccination on varicella epidemiology: Connecticut-2005-2008.J Infect Dis. 2011;203(4):509-12. DOI: 10.1093/ infdis/jiq081 PMID: 21199882

28. Marin M, Meissner HC, Seward JF. Varicella prevention in the United States: a review of successes and challenges. Pediatrics. 2008;122(3):e744-51. DOI: 10.1542/peds.2008-0567 PMID: 18762511

29. Lopez AS, Zhang J, Brown C, Bialek S. Varicella-related hospitalizations in the United States, 2000-2006: the 1-dose varicella vaccination era.Pediatrics. 2011;127(2):238-45. DOI: 10.1542/peds.2010-0962 PMID: 21199857

30. Zhou F, Harpaz R, Jumaan AO, Winston CA, Shefer A. Impact of varicella vaccination on health care utilization.JAMA. 2005;294(7):797-802. DOI: 10.1001/jama.294.7.797 PMID: 16106004

31. Shah SS, Wood SM, Luan X, Ratner AJ. Decline in varicellarelated ambulatory visits and hospitalizations in the United States since routine immunization against varicella. Pediatr Infect Dis J. 2010;29(3):199-204. DOI: 10.1097/ INF.obo13e3181bbf2ao PMID: 19949362

32. Davis MM, Patel MS, Gebremariam A. Decline in varicellarelated hospitalizations and expenditures for children and adults after introduction of varicella vaccine in the United States.Pediatrics. 2004;114(3):786-92. DOI: 10.1542/ peds.2004-0012 PMID: 15342855

33. Galil K, Brown C, Lin F, Seward J. Hospitalizations for varicella in the United States, 1988 to 1999.Pediatr Infect Dis J. 2002;21(10):931-5. DOI: 10.1097/00006454-200210000-00009 PMID: 12394815

34. Ratner AJ. Varicella-related hospitalizations in the vaccine era.Pediatr Infect Dis J. 2002;21(10):927-31. DOI: 10.1097/00006454-200210000-00008 PMID: 12394814

35. Reynolds MA, Watson BM, Plott-Adams KK, Jumaan AO, Galil K, Maupin TJ, et al. Epidemiology of varicella hospitalizations in the United States, 1995-2005. J Infect Dis. 2008;197(s2) Suppl 2;S120-6. DOI: 10.1086/522146 PMID: 18419384

36. Siedler A, Arndt U. Impact of the routine varicella vaccination programme on varicella epidemiology in Germany.Euro Surveill. 2010;15(13):19530.PMID: 20394710

37. Knuf M, Neiss A, Wutzler P. [Impact of universal varicella vaccination in Germany: an epidemiological and economic analysis]. Klin Padiatr. 2006;218(4):203-12. German. DOI: 10.1055/s-2005-836610 PMID: 16819701

38. Spackova M, Muehlen M, Siedler A. Complications of varicella after implementation of routine childhood varicella vaccination in Germany.Pediatr Infect Dis J. 2010;29(9):884-6. DOI: 10.1097/INF.ob013e3181e2817f PMID: 20442685

39. Azzari C, Massai C, Poggiolesi C, Indolfi G, Spagnolo G, De Luca $M$, et al. Cost of varicella-related hospitalisations in an Italian paediatric hospital: comparison with possible vaccination expenses. Curr Med Res Opin. 2007;23(12):294554. DOI: 10.1185/030079907X242610 PMID: 17937842

40. Thiry N, Beutels P, Tancredi F, Romanò L, Zanetti A, Bonanni P, et al. An economic evaluation of varicella vaccination in Italian adolescents. Vaccine. 2004;22(27-28):3546-62. DOI: 10.1016/j. vaccine.2004.03.043 PMID: 15315834

41. Coudeville L, Brunot A, Giaquinto C, Lucioni C, Dervaux B. Varicella vaccination in Italy : an economic evaluation of different scenarios.Pharmacoeconomics. 2004;22(13):839-55. DOI: $10.2165 / 00019053-200422130-00003$ PMID: 15329030

42. Bonanni P, Boccalini S, Bechini A, Banz K. Economic evaluation of varicella vaccination in Italian children and adolescents according to different intervention strategies: the burden of uncomplicated hospitalised cases.Vaccine, 2008;26(44):561926. DOI: $10.1016 /$ j.vaccine.2008.07.096 PMID: 18723062

\section{License and copyright}

This is an open-access article distributed under the terms of the Creative Commons Attribution (CC BY 4.0) Licence. You may share and adapt the material, but must give appropriate credit to the source, provide a link to the licence, and indicate if changes were made.

This article is copyright of the authors, 2016. 